\title{
Updating of mountain trails on the "Digital Japan Basic Map" using big data of walking paths
}

\author{
Kiyoaki NAKAMINAMI $^{\text {a, }}$, Koji OTSUKA ${ }^{\text {a }}$, Yoshikazu HONDA ${ }^{\text {a }}$ \\ ${ }^{a}$ Geospatial Information Authority of Japan, National Mapping Department, Geographical Name Information Division, \\ gsi-tozan@ml.mlit.go.jp
}

Keywords: Updating, Mountain trail, Big data, Digital Japan Basic Map

\begin{abstract}
:
Geospatial Information Authority of Japan (GSI) provides the "Digital Japan Basic Map" as fundamental geospatial information of Japan. Main items of the "Digital Japan Basic Map" such as major roads, large scale buildings and administrative boundaries are quickly and continuously updated as soon as useful source data are obtained from collaborating public facility administrators and local governments. On the other hand, other items are revised at relatively long interval using ortho images, urban planning base maps and other sources depending on the changes of national land throughout Japan.
\end{abstract}

Mountain trails are a part of the "Digital Japan Basic Map" as one of the road feature which should be updated quickly and continuously. When GSI provided the initial 1:25,000 scale topographic maps, which cover the whole area of national land and are one of the source of "Digital Japan Basic Map", GSI conducted field surveys and drew mountain trails using aerial photographs. They have been updated partly so far. When landslips occur, mountain trails easily change their locations. In the thickly wooded areas, they are difficult to draw using only aerial photographs, requiring time and labourconsuming field surveys. On the other hand, the primary cause of distress in mountainous areas is getting lost. Therefore providing accurate and updated maps is essential to decrease distress and to keep mountaineers safety.

People who use mountaineering applications on their smartphones and tablets are increasing more and more, as almost all smartphones and tablets have a GNSS module and provide locations on maps. The applications users post and share the information of their walking paths, which are recorded by their smartphones and tablets, on the web sites for the community of mountaineers. The more the number of the applications users increase, the more walking paths are stored as big data on the web sites.

GSI concluded the agreements between two private companies respectively which manage the web sites for the community of mountaineers in December, 2017. Thus GSI received enormous walking paths information as big data from the cooperating companies and commenced to update mountain trails using big data. GSI provided the first updated maps using big data of walking paths in March, 2018. Now GSI continues to update trails of major mountains all over Japan. GSI will quickly and continuously provide the accurate and updated maps using big data, contributing to the safety and convenience of mountaineers. 